\title{
Derivatives Trading and Negative Voting
}

\section{Citation}

Holger Spamann, Derivatives Trading and Negative Voting, Harvard Law, Economics, and Business Discussion Paper No. 730 (Sept. 10, 2012).

\section{Permanent link}

http://nrs.harvard.edu/urn-3:HUL.InstRepos:12331809

\section{Terms of Use}

This article was downloaded from Harvard University's DASH repository, and is made available under the terms and conditions applicable to Open Access Policy Articles, as set forth at http:// nrs.harvard.edu/urn-3:HUL.InstRepos:dash.current.terms-of-use\#OAP

\section{Share Your Story}

The Harvard community has made this article openly available.

Please share how this access benefits you. Submit a story.

Accessibility 
ISSN 1936-5349 (print)

ISSN 1936-5357 (online)

\title{
HARVARD
}

JOHN M. OLIN CENTER FOR LAW, ECONOMICS, AND BUSINESS

\author{
DERIVATIVES TRADING
}

AND NEGATIVE VOTING

Holger Spamann

Discussion Paper No. 730

09/2012

Harvard Law School

Cambridge, MA 02138

This paper can be downloaded without charge from:

The Harvard John M. Olin Discussion Paper Series:

http://www.law.harvard.edu/programs/olin_center/

This paper is also a discussion paper of the

John M. Olin Center’s Program on Corporate Governance. 


\title{
Derivatives Trading and Negative Voting
}

\author{
Holger Spamann*
}

September 4, 2012

\begin{abstract}
This paper exposits a model of parallel trading of corporate securities (shares, bonds) and derivatives in which a large trader can sometimes profitably acquire securities with their corporate control rights for the sole purpose of reducing the corporation's value and gaining on a net short position created through off-setting derivatives. At other times, the large trader profitably takes a net long position. The large trader requires no private information beyond its own trades. The problem is most likely to manifest when derivatives trade on an exchange and transactions give blocking powers to small minorities, particularly out-of-bankruptcy restructurings and freezeouts. JEL: G34, K22.
\end{abstract}

\footnotetext{
*Assistant professor, Harvard Law School. hspamann@law.harvard.edu. For comments and helpful discussions, I thank Ruchir Agarwal, Philippe Aghion, Jennifer Arlen, Lucian Bebchuk, Effi Benmelech, Ryan Bubb, Cansu Canca, Tom Cunningham, Einer Elhauge, Stavros Gadinis, Stefano Giglio, Ed Glaeser, Oliver Hart, Scott Hirst, Marcel Kahan, Louis Kaplow, David Mengle, Ivan Reidel, Andrei Shleifer, Lynn Stout, Andrew Tuch, Bernard Yeung, the Harvard Law School corporate faculty and corporate fellows lunch groups, and seminar participants at the economics departments of Harvard University and National University of Singapore (NUS), at NUS Business School, and at the law schools of UC Berkeley, University of Chicago, Columbia, Cornell, Duke, Emory, NYU, University of Pennsylvania, University of Virginia, USC, and Yale. For generous financial support, I thank the Program on Corporate Governance at Harvard Law School, a Terence M. Considine Fellowship provided through the John M. Olin Center for Law, Economics, and Business at Harvard Law School, and Harvard University. Part of this work was completed while I was visiting NUS; I am grateful to the University and especially to Ivan Png and Bernard Yeung for their hospitality.
} 
(c) 2012 Holger Spamann. All rights reserved.

\section{Introduction}

Securities regulators, practitioners, and legal commentators worry that derivatives may provide shareholders and creditors incentives to destroy value in their corporation. ${ }^{1}$ The basic concern is that if shareholders or creditors own a sufficient amount of off-setting derivatives such as put options or credit default swaps (CDS), any losses on their shares or debt will be more than off-set by the corresponding gains on their derivatives ("over-hedging"). In this case, shareholders and creditors benefit by using the control rights inherent in their shares or debt to reduce the corporation's value ("negative voting"). An important question that is generally not considered, however, is whether it would ever be profitable for shareholders or creditors to acquire so many derivatives in the first place. After all, any gains to shareholders and creditors come at the expense of their counterparties on their derivative contracts. These counterparties would therefore prefer not to sell the derivatives, or only at a price that compensates them for the future payouts, thus depriving shareholders and creditors of any profit in the overall scheme.

This paper argues that over-hedging and negative voting can indeed be profitable with a minimal and realistic degree of investor heterogeneity and asymmetric information. The paper presents a model of parallel trading of corporate securities (shares, bonds) and derivatives in which a large, strategic trader interacts with liquidity traders and competitive market makers. The key assumptions are that market makers cannot observe the large trader's orders directly, and cannot infer them from aggregate order flow because of fluctuating liquidity trades. In this case, market makers cannot predict how control rights will be exercised if the large trader only over-hedges some of the time. Prices will reflect some probability of negative voting, allowing the large trader to benefit from its private information about its own trades and expected vote. In effect, the large trader is exploiting private information about payoff uncertainty that the large trader itself creates. The large trader benefits at the expense of liquidity traders, whose trades provide camouflage to the

\footnotetext{
${ }^{1}$ Regulators: See, e.g., Securities and Exchange Commission, Concept Release on the U.S. Proxy System, 75 Fed. Reg. 42,982, 43,017-20 (July 22, 2010); Committe of European Securities Regulators, Public Statement of the Market Participants Consultative Panel CESR/10/567 (July 5, 2010), at 3-4. Practitioners: See, e.g., Soros (2010) and Sender (2009) (quoting from David Einhorn's letter to investors). Commentators: See in particular Martin and Partnoy (2005) and $\mathrm{Hu}$ and Black (2007, 2008).
} 
large trader.

The assumption that counterparties cannot observe the large trader's positions and hence its incentives for exercising control rights seems to capture many situations in real world derivative markets. This is obvious to the extent derivatives are traded on an exchange and centrally cleared. Such anonymous trading has long been the standard for equity options and is now generally mandated by the Dodd-Frank Act. But even when trading occurs over-the-counter (OTC), traders' positions and strategies are confidential and remain largely hidden from their counterparties (e.g., Avellaneda and Cont 2010 for the CDS market). To be sure, any market participant in an OTC market knows the identity of it direct counterparty, at least post-trade. But since dealers routinely enter into chains of hedging transactions (e.g., Stulz 2010), the ultimate buyer of protection will usually be unaware of the identity of the ultimate seller, and vice versa. ${ }^{2}$ In addition, investors can conceal their overall position even from their direct counterparties by splitting trades among many of them.

The foregoing assumption distinguishes the present paper from Bolton and Oehmke (2011) and Campello and Matta (2012). These very insightful papers analyze the effect of CDS availability on renegotiation in an incomplete contracting model of debt with strategic default. In their model, creditors' ability to hedge their exposure to the debtor with CDS contracts increases creditors' bargaining power in renegotiation. This reduces the incidence of strategic default and therefore has the beneficial effect of increasing the debt capacity of the firm; at the same time, overinsurance may lead to an inefficiently high frequency of bankruptcy. Crucially, these papers assume that the CDS protection sellers observe the exact position of the buyer-creditor, who therefore never gains from dealing in CDS as such. While this assumption is justified in many situations, the asymmetric information scenario considered in the present paper seems better suited to other situations, particularly for exchange trading of derivatives. In effect, a parallel reading of the aforementioned papers and the present one demonstrates the crucial importance of CDS market structure for discussing the costs and benefits of these derivatives.

Brav and Mathews (2011) present a model closely related to the present one in the context of equity trading with record date capture. ${ }^{3}$ Like the present paper, Brav and Mathews build

\footnotetext{
${ }^{2}$ Chen et al. (2011) report that dealers often do not hedge large trades right away but only in the course of several days. Unless default of the reference entity is imminent, however, this does not change the basic point here.

${ }^{3}$ Also see parallel work by Zachariadis and Olaru (2012), who also build on Kyle and Vila (1991) but consider only
} 
on the idea and basic model of Kyle (1984) and Kyle and Vila (1991): camouflaged by noise traders, a strategic trader can earn a trading profit if that trader has the power to influence the corporation's value upwards (downwards) only when going long (short). As Kyle and Vila note, it is not crucial that the large trader's influence (in Kyle and Vila, a takeover) improves the value of the corporation relative to the baseline of no large trader: any power to influence the value of the corporation produces opportunities for trading profits. Of course, the coupling of control rights to cash flow rights usually ensures that such power will only be exercised by those who would improve the firm value relative to the baseline. Brav and Mathews decouple control and cash flow rights, however, by allowing the large trader to sell shares, including short sales, between the record date (which determines voting rights) and the vote date, as is true in practice. Similarly, the present paper decouples cash flow rights and control rights through trading in derivatives. The papers then develop different aspects of the model. Brav and Mathews emphasize the trade-off between giving more weight to an informed trader's voice and the danger of value-destroying behavior. By contrast, the present paper focuses on the economic mechanism (section 2) and the institutional conditions (section 4) that allow profitable value-destroying behavior in the first place, highlighting the role of the trading environment (information and liquidity).

Empirical work on negative voting has been severely limited by the lack of investor-level position and voting data. Papers that have looked at correlations between the availability of CDS and corporate bankruptcy have found mixed results, depending on the time period studied and the construction of the sample (Peristiani and Savino 2011; Bedendo et al. 2012). In the future, regulators may gain access to the requisite data for more probative empirical studies. In the meantime, gaining a firm theoretical understanding of the question remains of pressing importance.

\section{The Economic Mechanism}

To facilitate understanding of the formal model presented in the next section, this section will lead with a verbal description of the main economic mechanism at work.

Imagine that two assets trade in a market with three types of participants. The traded assets

binary trading choices (i.e., trade or no trade) and add another strategic player, namely the firm manager who makes a take-it-or-leave-it restructuring offer. With these assumptions, they find that value-destroying behavior occurs only if the hedge fund has a pre-existing position in the firm's debt, or debt and equity markets do not incorporate the same information. 
are bonds (publicly traded debt claims) and credit insurance on those bonds. The market participants are a hedge fund, numerous benign traders such as pension funds and mutual funds, and numerous competitive financial institutions that act as market makers. The benign traders buy and sell random quantities regardless of price for exogenous purposes such as fulfilling redemptions or purchases, portfolio rebalancing, or compliance with fund risk policies. Competition between market makers ensures that the benign traders always obtain prices equal to the value that is expected given publicly available information. The precise structure of trading will be discussed later.

After trading, the value of the bonds - and hence the payouts on credit insurance contracts will be determined by a bondholder vote on a proposed restructuring. For illustrative purposes, assume that the bonds will be worthless if creditors reject the restructuring, but pay the full face amount if creditors accept the restructuring. Conversely, credit insurance will pay out nothing if the restructuring succeeds, and will pay the full insured amount if the restructuring fails. Naturally, bondholders will accept the restructuring unless they own more than full credit insurance on their bonds, i.e., unless they are over-hedged.

To keep things simple, assume that only one market participant - the hedge fund - is ruthless enough to consider over-hedging and negative voting. That is, only the hedge fund would purchase more credit insurance than bonds and attempt to block the restructuring. One can imagine that reputational or regulatory concerns prevent other market participants from considering this strategy. The probability that the hedge fund would be able to block the restructuring is increasing in the number of bonds that the hedge fund owns. The willingness of the hedge fund to block the restructuring depends only on the hedge fund's relative holdings of bonds and credit insurance: if the hedge fund owns more credit insurance, the hedge fund will attempt to block the restructuring; otherwise, it will not.

These assumptions imply that the expected value of the bonds - and the expected payouts on the credit insurance - depends entirely on how many bonds and how much credit insurance the hedge fund ends up owning. The problem for market makers is that they do not know the hedge fund's trades and ultimate position, and hence cannot determine exactly how much the bonds or credit insurance will be worth. The crucial but realistic assumption is that market makers cannot observe the hedge fund's trades. In particular, the hedge fund can conceal its trades by placing orders through different brokers. Market makers are able to observe aggregate market turnover - 
through information repositories, or exchange data -, but these aggregate numbers compound the hedge fund's trades with the random trades of benign traders.

The best that market makers will be able to do is to form expectations of the hedge fund's positions based on the aggregate trading data. Before discussing this inference problem, however, it is instructive to consider what would happen if market makers' expectations did not depend on trading volume. Consider two extreme cases. If market makers believed that the hedge fund will block the restructuring, the bond price would be zero (recall that competition between market makers will push prices to expected value), while credit insurance would cost exactly the insured amount. In this case, the hedge fund could make (unlimited) profits by buying (all the) bonds for free, selling (unlimited amounts of) insurance, and not preventing the restructuring. At the other extreme, if market makers believed that the hedge fund will not block the restructuring, the bond price would be equal to its face amount, while credit insurance would be costless. In this case, the hedge fund could make unlimited profits by buying unlimited amounts of credit insurance for free and just enough bonds to block the restructuring.

To analyze how market makers are going to form beliefs about the hedge fund's positions from aggregate market data, it is necessary to specify the trading process in more detail. The model considers the simplest possible market with only one round of trading. First, the hedge fund and liquidity traders submit their orders (buys and sells). Second, market makers observe aggregate orders. Third, market makers fill all these orders at competitive prices, i.e., prices that correspond to their best estimate of the probability that the hedge fund will block the restructuring.

In this setup, market makers beliefs about the hedge fund's position will be based on their observation of aggregate orders in combination with their prior beliefs about the distribution of benign traders' orders. In particular, when the demand for bonds or derivatives is extremely high or low (this includes negative demand), market makers will assume with high probability that this demand emanates mostly from the hedge fund if and because benign traders never submit such large orders. For more moderate values, market makers will not know if they result from relatively high demand by the hedge fund and relatively low demand by the benign market participants, or vice versa. In this case, market makers must assign probability estimates based on the relative likelihood of these two scenarios, and prices will reflect weighted average values.

These average prices enable the hedge fund to profit from mixing both strategies. Sometimes 
the hedge fund profits by over-hedging and blocking the restructuring. At other times, the hedge fund gains by not over-hedging and letting the restructuring proceed because it can buy the bond at a price discount, and sell credit insurance at a price premium, that reflect the possibility of the restructuring being blocked. To be sure, the hedge fund cannot predict benign traders demand. If high (low) demand by the hedge fund coincides with high (low) demand by benign traders, market makers can infer the hedge fund's positions and hence accurately predict bond and insurance payoffs. In this case, the hedge fund does not make any profits. When high hedge fund demand coincides with low demand by benign traders and vice versa, however, the hedge fund makes a trading profit. In effect, the hedge fund is trading on private information on its own value-relevant strategy.

Where do the hedge fund's profits come from? Competitive market makers always trade for prices that are equal to expected value, given their information. Consequently, market makers make zero profits or losses. The hedge fund's profits come out of the pockets of the benign traders. They tend to sell many derivative contracts when pay-outs on the contracts will turn out to be high relative to the contracts' price, and they tend to buy many contracts when pay-outs will turn out to be low relative to the contracts' price.

As a final note, the size of the hedge fund's positions depends on trading costs such as commissions, bid-ask spreads, or margin requirements, and the variability of benign traders' demand. The higher the variability of benign traders' demand, the bigger the stakes that the hedge fund can hope to buy without being discovered, and hence the larger the trading profits that the hedge fund can make. The higher the trading costs, the more conservatively the hedge fund will trade. In the extreme, trading costs can be so high as to make it impossible for the hedge fund to make any profits. In this sense, a more "liquid" market facilitates over-hedging and negative voting.

\section{The Formal Model}

\subsection{Model Setup}

This subsection introduces the setup of the model: the two types of traded assets (securities and

derivatives), the three types of market participants (hedge fund, liquidity traders, and market makers), and trading including information. It concludes with some remarks on this setup. 


\subsubsection{Timeline}

The timeline of actions is as follows (details to follow in subsequent subsections):

1. The hedge fund and liquidity traders submit their orders.

2. The market makers observe only net market demand, which combines the hedge fund's and the liquidity traders' orders. Based on this observation, market makers update their beliefs about the expected value of the securities and derivatives. At these values (prices), they fill all net orders.

3. Security holders choose between two actions by some voting mechanism.

4. Payoffs are realized.

\subsubsection{Traded assets}

There are two traded ${ }^{4}$ assets with perfectly negatively correlated payoffs: securities, which will throughout be denoted by the letter $X$, and derivatives, which will throughout be denoted by the letter $Y$. If the security pays $v$, the derivative pays $1-v$. Consequently, the derivative can be interpreted as an insurance claim on the security. In particular, if the security were a bond, the derivative could be a credit default swap; if the security were a share, the derivative could be a total equity return swap.

The number of securities is normalized to one (of which infinitesimal divisions are traded). The derivative is a synthetic asset; hence its net supply is zero but unlimited amounts can be sold and bought. Short-selling is allowed for both derivatives and securities.

The security payoff $v$ depends on a binary choice between two actions, which is determined by a vote of the security holders. For example, if the security is a bond, the choice could be whether or not to agree to a proposed restructuring; if the security is a share, it could be whether or not to agree to a merger. Normalize the payoff when the "right" decision is taken to $v=1$, and when the "wrong" decision is taken to $v=0$.

Each security provides one vote; derivatives do not provide any votes.

\footnotetext{
4 "Trading" does not need to be understood literally in this model. In particular, it is possible that the derivative is a contract that is sold over the counter. What matters is that there be an active market for the contract in which various parties can act as sellers or buyers, which is true for many derivative markets.
} 
Naturally, a rational, informed, and unhedged security holder would always vote for the "right" decision in order to receive $v=1$. As will be discussed in the next subsection and the concluding remarks on the model setup, this is indeed what all security holders are assumed to do. The one exception is the hedge fund if and because the hedge fund owns more derivatives than securities, i.e., if the hedge fund owns securities but is over-hedged. The hedge fund's ability to block the "right" decision depends on whether the hedge fund's security-holding is above some voting threshold. The voting threshold is assumed to be a random variable distributed on $[0,1]$ according to the continuous cdf $F(\cdot)$ with $F(0)=0$ and $F(1)=1$. The randomness captures unexpected variation in voter participation, uncertainty arising from legal concerns, different formal thresholds for different types of decisions, etc. The voting threshold is assumed to be independent of other exogenous variables in the model, and it will be independent of any trading activity since it will be only revealed after all trading occurs. Let $\underline{x} \equiv \max \{x \mid F(x)=0\} \geq 0$.

\subsubsection{Market Participants}

There are three types of risk-neutral market participants: liquidity traders, one hedge fund, and competitive market makers.

Liquidity traders The liquidity traders do not act strategically. They exogenously trade quantities $\tilde{x}$ and $\tilde{y}$ of securities and derivatives, respectively, where positive numbers indicate that the liquidity traders are buying, and negative numbers indicate that they are selling. These trades are not sensitive to price, and the source of these trades is not modelled. To motivate these trades and their price insensitivity, one may think of large institutional investors and their regulatory constraints. For example, certain pension funds might be forced to sell bonds following a credit downgrade of the borrower. Similarly, financial institutions might be forced to purchase credit default swaps on certain bonds they hold. Or one may think of mutual funds having to liquidate part of their portfolio to meet redemption requests.

Liquidity traders' demand for derivatives, $\tilde{y}$, is stochastic (keeping in mind that the "demand" can be negative). With probability $(1-\lambda)$, the demand is low $(\tilde{y}=\underline{y})$, while with probability $\lambda$, demand is high $(\tilde{y}=\bar{y})$. Define the difference between these demand realizations as $\delta \equiv \bar{y}-\underline{y}>0$.

For simplicity, liquidity traders' demand for securities, $\tilde{x}$, is assumed to be constant. 
Hedge fund The hedge fund does act strategically. Initially, the hedge fund does not hold any securities or derivatives. It purchases quantities $x$ and $y$ of securities and derivatives, respectively, taking into account the effect of its trades on the price (as explained below), its own voting power, and its own voting incentives. As explained in the previous subsection, holding $x>\underline{x}$ securities gives the hedge fund the voting power to implement the "wrong" decision with probability $F(x)>0$ . Of course, the hedge fund will only have an incentive to use this power if $y \geq x$. The hedge fund incurs a financing cost $C(x, y)$ with $C(0,0)=\min _{x, y} C(x, y)=0, \operatorname{sign}\left[C_{1}(x, \cdot)\right]=\operatorname{sign}(x)$ and $\operatorname{sign}\left[C_{2}(\cdot, y)\right]=\operatorname{sign}(y)$.

Market makers The market makers absorb any excess demand $(\hat{x}, \hat{y}) \equiv(\tilde{x}+x, \tilde{y}+y)$. Since they are risk-neutral, infinitesimally small, and in perfect competition with one another, they purchase or sell these quantities at prices that equal expected value, as explained in more detail below. Market makers have rational expectations, i.e. they update their beliefs about $(x, y)$ upon observing the net demand of securities $(\hat{x}, \hat{y})$.

\subsubsection{Remarks on the model setup}

As noted in the introduction, the model builds on Kyle (1984) and Kyle and Vila (1991). Following Brav and Mathews (2011), however, the model dispenses with the simplifying assumption in Kyle (1984) and Kyle and Vila (1991) that the hedge fund has private information about noise trades. That is, the model does not contain any exogenous asymmetric information; the only asymmetric information pertains to the hedge fund's own strategy. Also as in Brav and Mathews (2011), the paper explicitly models as voting rights the source of the hedge fund's power to influence the corporation's value, which remained a black box in Kyle and Vila (1991). While Brav and Mathews (2011) break the link between voting and cash flow rights through trading between record and voting date, the present paper does so with a second traded asset, the derivative. The addition of trading costs is novel.

The model assumes that the hedge fund is able to acquire any amount $x$ of securities that it desires. In particular, this ability does not depend on the amount $\tilde{x}$ supplied by liquidity traders. In reality, it may often be difficult or impossible to acquire large blocks of shares or bonds. There are, however, many situations in which exogenous sales of securities $\tilde{x}$ are large, and the reader may 
restrict the applicability of the model to such situations. For example, many institutional investors sell all their holdings of a bond if the bond's credit rating drops below investment grade (Da and Gao 2009). Moreover, in the model, an upper bound on the amount $x$ of securities that the hedge fund can acquire would not change the hedge fund's strategy, and the only change from the results presented below would be that the hedge fund might have to settle for the upper bound rather than its preferred, higher position (i.e., one would observe corner solutions).

Relatedly, the assumption that large purchases have no price impact beyond the probability update by the market makers is not literally true. To go back to the acquisition of securities, it would presumably become harder and harder to find additional securities as the hedge fund's position grows, and this would be reflected in higher trading costs for larger positions. Mathematically, however, the assumption of a financing cost for the hedge fund has the same effect as assuming increasing trading costs for larger blocks, so that nothing substantive hinges on the assumption of constant prices conditional on the updated probability.

Finally, it is a strong assumption that only the one hedge fund is ready to buy large stakes, and to consider over-hedging its securities position and to vote the securities for the "wrong" decision. This excludes, first, that any of the other market participants in the model, namely individual market makers and liquidity traders, who must hold the remaining supply of securities, would ever hold more derivatives than securities, or if they did, that they nevertheless voted for the "right" decision. One justification for this could be institutional, namely that reputational concerns or sheer apathy prevent market makers and liquidity traders to vote for the "wrong" decision, or to over-hedge their securities position in the first place. One can also view the model as an illustration of how "negative voting" can interfere with the smooth operation of a liquid, perfect market for securities; in this view, the true equilibrium would be more complicated, and the model merely illustrates why the market cannot be perfect.

Second, the above assumptions rule out strategic competition with a second large player. For example, one can imagine a second hedge fund trying to share the spoils, or to buy up enough of the security at a low price to prevent the first hedge fund from ever winning a vote for the "wrong" decision. From a practical point of view, however, adding another strategic player would complicate the model but not eliminate the underlying economic problem. For example, even if the security were trading at deep discount because of the hedge fund's presence, another large player 
could not necessarily profitably intervene by buying up the entire supply of securities if and because that second large player incurs similar financing cost as the first hedge fund. Moreover, even if the second large player could profitably do this, then in expectation the price of the security would re-adjust to 1 , so that the strategy would end up being not profitable after all. Subsection 3.5 below states this argument formally.

\subsection{Equilibrium Concept}

In principle, the equilibrium concept employed here is Perfect Bayesian Equilibrium, including in particular subgame perfection and rational, Bayesian expectations. The above assumptions on individual behavior, however, allow summarizing the strategic interaction in two simple equilibrium conditions that greatly facilitate discussion of the results (cf. Kyle 1984, 1985; Kyle and Vila 1991). The assumption that liquidity traders' trades are exogenous means that liquidity traders decisions need not be explicitly considered at all.

First, the assumption that market-makers act as competitive, risk-neutral price takers and absorb any net demand $(\hat{x}, \hat{y})$ means that their behavior can be summarized by the price function. The price function is in turn pinned down by market-makers' rational expectations about the security's payoff:

Efficient markets: for some $\theta(\cdot, \cdot), P_{y}(\hat{x}, \hat{y})=1-P_{x}(\hat{x}, \hat{y})=\theta(\hat{x}, \hat{y}) \in[0,1]$

where $P_{x}(\hat{x}, \hat{y})$ is the price of securities, $P_{y}(\hat{x}, \hat{y})$ is the price of derivatives, and $\theta(\hat{x}, \hat{y}): \mathbb{R}^{2} \rightarrow[0,1]$ is a probability belief compliant with Bayes' rule that the security will pay zero, all conditional on observed net demand of securities and derivatives, $(\hat{x}, \hat{y})$. Some elements of this efficient markets condition would not require rational expectations: The absence of arbitrage alone would imply that derivative and security prices lie between zero and one and sum to one because the two assets are perfectly negatively correlated, together always pay one, and individually never pay less than zero or more than one. The requirement that $\theta(\cdot, \cdot)$ comply with Bayes' rule, however, imposes important additional constraints that will be discussed in subsection 3.3 below.

Second, the hedge fund only has two meaningful choice variables, namely its trades $x$ and $y$. 
That is, the hedge fund's equilibrium strategy is captured by

$$
\text { Profit maximization: } \sigma\left(x^{\prime}, y^{\prime}\right)>0 \Rightarrow\left(x^{\prime}, y^{\prime}\right) \in \arg \underset{(x, y)}{\max } \mathbb{E}_{\tilde{y}}[\Pi(x, y, \theta(x+\tilde{x}, y+\tilde{y}))] \text {, }
$$

where $\Pi(x, y, \theta)$ is the hedge fund's profit given its choice of trades $(x, y)$ and $\theta$, and $\sigma(x, y) \in$ $[0,1]$ is the probability with which the hedge fund chooses trades $(x, y)$. The hedge fund's choice of $\sigma(x, y)$ will of course take into account the effect of its trades on prices, i.e., on the probability inference of the market makers, $\theta(\hat{x}, \hat{y})$. In that sense, the efficient market condition implies an inverse demand curve against which the hedge fund maximizes.

In principle, the hedge fund also needs to choose its vote at the voting stage. This choice, however, is trivially determined by its holdings of securities and derivatives. If the hedge fund holds more securities than derivatives $(x>y)$, it will vote for the "right" decision. In the opposite case $(x<y)$, it will vote for the "wrong" decision. To be sure, mixing is possible if $x=y$, but this will never occur unless $x=y=0$ because given trading cost, it would not be profitable for the hedge fund (see proof of Lemma 1).

\subsection{Equilibrium in the General Case}

The equilibrium of the model depends principally on the hedge fund's trading cost function. If the costs are large, they outweigh any trading gains, such that abstention $(x=y=0)$ is the hedge fund's only viable strategy. On the other hand, if the hedge fund's costs are low, it always pays for the hedge fund to try its luck - to the extent noise trades camouflage the hedge fund's trade, market makers cannot be sure about whether the hedge fund is long or short and must choose some intermediate price, at which the hedge fund can turn a trading profit. Proposition 1 below states this formally; Lemma 1 prepares the ground by setting forth the equilibrium inference function.

Lemma 1 One inference function sustaining all possible equilibria is

$$
\theta_{e q}(\hat{x}, \hat{y}) \equiv\left\{\begin{array}{cc}
0 & \text { if } \hat{x}-\tilde{x} \leq \underline{x} \text { or } \hat{y}-\underline{y}<\hat{x}-\tilde{x} \\
F(\hat{x}-\tilde{x}) & \text { if } \underline{x}<\hat{x}-\tilde{x}<\hat{y}-\bar{y} \\
\max \left\{0, \min \left\{F(\hat{x}-\tilde{x}), \theta^{*}(\hat{x}, \hat{y})\right\}\right\} & \text { otherwise }
\end{array}\right.
$$


where $\theta^{*}(\hat{x}, \hat{y}) \equiv \frac{F(\hat{x}-\tilde{x})(1-\lambda)[(\hat{y}-\underline{y})-(\hat{x}-\tilde{x})]+C(\hat{x}-\tilde{x}, \hat{y}-\bar{y})-C(\hat{x}-\tilde{x}, \hat{y}-\underline{y})}{\lambda[(\hat{x}-\tilde{x})-(\hat{y}-\bar{y})]+(1-\lambda)[(\hat{y}-\underline{y})-(\hat{x}-\tilde{x})]}$.

Proof. See the appendix.

Briefly, the reasoning behind $\theta_{e q}$ is as follows. First, some market demand realizations $(\hat{x}, \hat{y})$ fully reveal the hedge fund's incentives, such that $\theta$ must be equal to 0 or $F(\hat{x}-\tilde{x})$, as the case may be (the hedge fund's voting power can always be inferred from market demand because liquidity traders' demand for securities $\tilde{x}$ is non-stochastic). Second, at other market demand realizations, defining $\theta_{e q}$ to equate expected hedge fund profits from the long and short trades that could generate this $(\hat{x}, \hat{y})$ sustains mixing if these are equilibrium trades, and optimally deters deviations if these are off-equilibrium trades.

Proposition 1 The hedge fund's equilibrium (expected) profits are $\max \left\{0, \pi^{*}\right\}$, where

$$
\begin{aligned}
\pi^{*} \equiv & \max _{\omega} \pi(x, y) \\
\omega \equiv & \{(x, y) \mid x>\underline{x}, y \in[x-\delta, x]\} \\
\pi(x, y) \equiv & \frac{F(x) \lambda(1-\lambda)(x-y)(y+\delta-x)}{\lambda(x-y)+(1-\lambda)(y+\delta-x)} \\
& -\frac{\lambda(x-y) C(x, y+\delta)+(1-\lambda)(y+\delta-x) C(x, y)}{\lambda(x-y)+(1-\lambda)(y+\delta-x)} .
\end{aligned}
$$

The hedge fund's equilibrium strategies depend on $\pi^{*}$ :

(a) If $\pi^{*}<0$, the unique equilibrium is for the hedge fund not to trade at all $(x=y=0)$.

(b) If $\pi^{*}>0$, any strategy such that $\sum_{\left(x^{*}, y^{*}\right) \in \arg \max _{\omega} \pi(x, y)}\left[\sigma\left(x^{*}, y^{*}\right)+\sigma\left(x^{*}, y^{*}+\delta\right)\right]=1$ and $\sigma\left(x^{*}, y^{*}\right)>0 \Rightarrow \frac{\sigma\left(x^{*}, y^{*}\right)}{\sigma\left(x^{*}, y^{*}+\delta\right)}=\frac{1-\lambda}{\lambda}\left[\frac{F\left(x^{*}\right)}{\theta^{*}\left(x^{*}+\tilde{x}, y^{*}+\bar{y}\right)}-1\right] \forall\left(x^{*}, y^{*}\right) \in \omega$ is an equilibrium; the equilibrium is unique if and only if $\arg \max _{\omega} \pi(x, y)$ is unique.

(c) If $\pi^{*}=0$, any linear combination of (a) with strategy profile (b) is an equilibrium.

Proof. By construction, $\pi^{*}$ coincides with the highest non-negative expected profit, if any, that the hedge fund can obtain from trades $(x, y) \in \omega$ given $\theta_{\text {eq }}$, since $\pi(x, y)=$ $\lambda(x-y) \theta^{*}(x+\tilde{x}, y+\bar{y})-C(x, y)$ coincides with $\mathbb{E}_{\tilde{y}}\left[\Pi\left(x, y ; \theta_{e q}(\cdot, \cdot)\right) \mid(x, y) \in \omega\right]$ unless $\theta_{e q}$ is truncated, which only occurs where expected profits are negative (see part (2)(b) of the proof of Lemma 1). The maximum $\pi^{*}$ exists because $\pi$ is a continuous function on the closed interval $\omega$. Any trade $\left(x^{*}, y^{*}\right)$ generating $\pi^{*}$ - and the trade $\left(x^{*}, y^{*}+\delta\right)$, which yields identical profits by construction of $\theta^{*}-$ will (strictly) dominate not trading $(x=y=0)$ if $\pi^{*}$ is (strictly) 
greater than zero; otherwise not trading strictly dominates. If more than one trade generates $\pi^{*}$, the hedge fund is indifferent between them and can mix them in any proportion. Mixing optimal trade pairs $\left(\left(x^{*}, y^{*}\right),\left(x^{*}, y^{*}+\delta\right)\right)$ in the stated proportions ensures that $\theta_{e q}\left(x^{*}+\tilde{x}, y^{*}+\bar{y}\right)=$ $\theta_{e q}\left(x^{*}+\tilde{x}, y^{*}+\delta+\underline{y}\right)=\frac{F\left(x^{*}\right)(1-\lambda) \sigma\left(x^{*}, y^{*}+\delta\right)}{(1-\lambda) \sigma\left(x^{*}, y^{*}+\delta\right)+\lambda \sigma\left(x^{*}, y^{*}\right)}=\operatorname{Pr}(v=0 \mid \hat{x}, \hat{y})$ is correct. If the hedge fund does not trade, the inference $\theta_{e q}(\tilde{x}, \underline{y})=\theta_{e q}(\tilde{x}, \bar{y})=0$ is correct because the hedge fund will not be able to influence the decision, so $\operatorname{Pr}(v=1 \mid \hat{x}, \hat{y})=1$.

It remains to be shown that only trades $(x, y) \in \omega$ need to be considered in the search for a profitable trade. Given the inference function $\theta_{\text {eq }}$, the hedge fund's trading profits are zero regardless of the noise realization unless $x-\delta \leq y \leq x+\delta$ and $x>\underline{x}$, and thus expected profits for such trades are negative given positive trading costs. ${ }^{5}$ Moreover, by construction (see proof of Lemma 1), $\theta_{\text {eq }}$ ensures that for each trade $(x, y)$ such that $\underline{x}<x \leq y \leq x+\delta$, there is a corresponding trade $(x, y-\delta) \in \omega$ that yields equal expected profits unless expected profits for both trades are negative.

Corollary 1 There always exists a non-zero cost function $C(\cdot, \cdot)$ such that a mixed equilibrium exists.

Proof. If $C(x, y)=0 \forall(x, y)$, then $\pi^{*}=\max _{\omega} \frac{F(x) \lambda(1-\lambda)(x-y)(y+\delta-x)}{\lambda(x-y)+(1-\lambda)(y+\delta-x)}>0$. The proof then follows by continuity of $\pi(\cdot, \cdot ; C(\cdot, \cdot))$ in $C(\cdot, \cdot)$.

\subsection{Equilibrium with quadratic cost, uniform voting threshold distribution, and symmetric liquidity trades}

To gain further insight into the properties of the model's equilibrium, this subsection analyzes the special case

$$
\begin{aligned}
C(x, y) & =\frac{c}{2}\left(x^{2}+y^{2}\right), \\
F(x) & =\max \{0, \min \{x, 1\}\}, \\
\lambda & =\frac{1}{2},
\end{aligned}
$$

\footnotetext{
${ }^{5}$ Regardless of the noise realization, trading profits are $(x-y) \theta(x+\tilde{x}, y+\tilde{y})=(x-y) \cdot 0=0$ if $y<x-\delta$, $(y-x)[F(x)-\theta(x+\tilde{x}, y+\tilde{y})]=(y-x)[F(x)-F(x)]=0$ if $y>x+\delta$, and $(x-y) \cdot 0=(y-x)(0-0)=0$ if $x \leq \underline{x}$.
} 
where $c>0$. Using Proposition 1, it is easy to verify that the hedge fund's optimal securities trade in this case is

$$
x^{*}=\frac{\delta}{16 c}
$$

together with either of

$$
\begin{aligned}
& y_{1}^{*}=x^{*}-\frac{\delta}{2}, \text { or } \\
& y_{2}^{*}=x^{*}+\frac{\delta}{2},
\end{aligned}
$$

provided that $0<\delta \leq 16 c \leq 2 \sqrt{2}$ (for larger $c$, expected profits from trading would be negative, so abstention would be optimal; for larger $\delta \leq \frac{1+\sqrt{1-32 c^{2}}}{2 c}$, the corner solution $x^{*}=1$ and $y_{1,2}^{*}=1 \pm \frac{\delta}{2}$ entails).

Not surprisingly then, the hedge fund becomes more aggressive ( $x^{*}$ increases) as the market becomes noisier and hence provides more camouflage ( $\delta$ increases), and as the costs of trading decrease ( $c$ decreases). This translates into a higher unconditional probability that the "wrong" decision will be adopted. With symmetric noise $\left(\lambda=1-\lambda=\frac{1}{2}\right)$ and a unique trading equilibrium, this probability is

$$
\begin{aligned}
\operatorname{Pr}(v=0) & =F\left(x^{*}\right) \sigma\left(x^{*}, y_{2}^{*}\right) \\
& =\frac{F\left(x^{*}\right)(1-\lambda) \sigma\left(x^{*}, y_{2}^{*}\right)}{(1-\lambda) \sigma\left(x^{*}, y_{2}^{*}\right)+\lambda \sigma\left(x^{*}, y_{1}^{*}\right)} \\
& =\theta_{e q}\left(x^{*}+\tilde{x}, y_{2}^{*}+\underline{y}\right) \\
& =\frac{\delta}{16 c}\left(\frac{1}{2}-2 c\right) .
\end{aligned}
$$

This is increasing in the amount of "noise" or demand fluctuation, $\delta$, and decreasing in the trading cost or market illiquidity, $c$. The liquidity traders' trading losses $\frac{\delta^{2}}{128 c}(1-4 c)$ are also increasing in the amount of "noise" or demand fluctuation, $\delta$, and decreasing in the trading cost or market illiquidity, $c$.

At least in this special case, the model therefore shows that increasing liquidity $(c)$ and market size $(\delta)$ aggravate the problem analyzed in this paper. 


\subsection{Multiple Hedge Funds}

Explicitly modelling the interaction of multiple hedge funds is far from straightforward, and will not be attempted here. As hinted above in subsection 3.1.4, however, one can at least state that problems of negative voting would persist in the presence of multiple strategic traders:

Corollary 2 Regardless of the number of hedge funds, the equilibrium $x=y=0$ exists if and only if $\pi^{*}<0$.

Proof. If $\pi^{*} \leq 0$ and market makers' inference function is $\theta_{\text {eq }}$, no individual hedge fund can profitably deviate by trading, while market makers correctly infer that the possibility of the "wrong" decision being adopted is zero. Conversely, if $\pi^{*}>0$, then any one hedge fund would be better off trading regardless of the inference function (recall that $\theta_{\text {eq }}$ minimizes the maximum possible trading profit), so $x=y=0$ cannot be an equilibrium. The presence of other non-trading hedge funds is irrelevant to this argument.

\section{Discussion}

This section considers economic and legal constraints that curtail over-hedging and negative voting. In particular, the section explains why the problem is much more likely to arise with derivatives than with alternative, more traditional hedges, what "natural" and regulatory barriers currently limit the problem, and in which situations the problem is therefore most likely to manifest. It argues that the problem is likely to be most acute in out-of-bankruptcy restructurings and freezeouts, which can be blocked by a relatively small minority stake, and arguably legally so.

\subsection{Derivatives vs. other hedges}

The first question to ask is why over-hedging is specifically a problem of derivatives. In principle, over-hedging can occur with any investment that is negatively related to the shares or debt at issue. Some examples include parallel investments in competing firms, parallel investments in both the acquiror and the target of a merger transaction, parallel investments in different securities of the same firm, or selling short some amount of a security while holding on to a smaller amount. These other investments, however, are either not perfectly correlated with the shares or debt and hence 
represent higher risk, or they are only available in particular situations, or they are available only in small quantities or at higher cost, or all of the above. These shortcomings severely limit the facility, frequency, and extent to which these other investments could enable over-hedging.

By contrast, derivatives are designed to be perfectly (negatively) correlated with the payoffs of shares or debt. Many derivatives markets, such as those for equity options, are highly liquid at all times. Even those that are not, such as single-name CDS, exhibit liquidity spikes around key events when over-hedging is most profitable, such as changes in credit outlook for CDS (Chen et al. 2011). In general, the rapid growth of derivatives markets over the last decade or two means that derivatives are in principle available in high volumes at low prices (spreads). It is not unusual that the face amount of derivatives written on the shares or debt of an individual company exceeds the amount of shares or debt issued by that company (Stulz 2010).

\subsection{Required control stakes}

Even if derivatives are available, it might seem an implausible proposition to acquire and overhedge a voting majority (51\%) of a corporation's shares or publicly traded debt. Such quantities of shares/debt and derivatives may not even be available on the market, and if they were, could hardly be acquired in secret and without strongly affecting prices. For shares, acquiring such quantities would also trigger disclosure and other obligations under corporate and securities laws and, in most U.S. corporations, the "poison pill." 6

Many relevant decisions, however, can be affected by much smaller percentages of shares or debt. One possibility is that an over-hedged shareholder or creditor joins forces with some other constituency pursuing interests other than maximizing share or debt value, such as a corporate insider.

More importantly, some corporate decisions provide blocking power to relatively small minorities. In particular, out-of-bankruptcy restructurings tend to set acceptance thresholds around 95\%, providing blocking rights to $5 \%$ or even less of the outstanding debt. Importantly, restructurings

\footnotetext{
${ }^{6}$ See in particular section 13(d) of the Exchange Act, which requires disclosure of equity ownership stakes above $5 \%$ and arguably of any hedges relating thereto (cf. discussion in the next section), and section 16 of the Exchange Act, which forces $10 \%$ shareholders to disclose their hedges (sec. 16(a)) and disgorge short-swing trading profits (sec. 16(b)). Moreover, section 16(c) prohibits 10\% shareholders from engaging in short sales, and rule 16c-4 explicitly extends this to over-heding using puts, while they are a $10 \%$ shareholder, thus outlawing any strategy of acquiring a voting stake first and over-hedging it later (but not the other way around).
} 
that do not bind all holders, such as a standard debt exchange, do not constitute a credit event under the prevailing CDS documentation and hence do not trigger settlement of the CDS. ${ }^{7}$ Practitioners suspect that over-hedging and negative voting are common in out-of-bankruptcy restructurings. ${ }^{8}$ In addition to restructurings, small stakes may be sufficient to affect freeze-out mergers. Majorityof-the-minority conditions in freeze-outs can give blocking rights to as little as a few percent of the corporation's outstanding equity. ${ }^{9}$

\subsection{Legal constraints}

At least in the U.S., current law only provides incomplete protection against over-hedging and negative voting. With respect to formal voting, U.S. law arguably provides some protection, but enforcement may be hindered by a lack of disclosure. Outside of formal voting, negative voting and over-hedging are arguably entirely unregulated.

Under $§ 1126(\mathrm{e})$ of the U.S. Bankruptcy Code, bankruptcy judges have the power to disallow votes by a creditor "whose acceptance or rejection of [a reorganization] plan was not in good faith." In a recent decision, the U.S. Bankruptcy Court for the Southern District of New York held, obiter, that this provision would justify disqualification of votes by over-hedged creditors. ${ }^{10}$ Bankruptcy courts will generally not know, however, if creditors are over-hedged. Current bankruptcy rules do not require disclosure of hedging transactions relating to debt claims filed in the bankruptcy.

For shares, the Delaware Supreme Court recently recognized "[a] Delaware public policy of guarding against the decoupling of economic ownership from voting power." 11 There is thus reason to believe that Delaware courts would at least seriously consider a remedy against voting by overhedged shareholders. Section 13(d)(1)(E) of the Exchange Act arguably requires that owners of 5\% or more of a corporation's stock disclose hedging transactions, but in practice market participants have not done so effectively. To address the enforcement problem, commentators have advocated stricter disclosure obligations. For example, Hu and Black $(2006,885)$ argue that voting by over-

\footnotetext{
${ }^{7}$ Cf. Art. 4.7(a) of the 2003 ISDA Credit Derivative Definitions, as amended by the "Small Bang Protocol," available at http://www.isda.org/publications/pdf/July-2009-Supplement.pdf.

${ }^{8}$ Author's conversation with the head of the restructuring practice of a major New York law firm.

${ }^{9}$ Such majority-of-the-minority conditions have been imposed by Delaware courts as a condition for obtaining favorable review of the consideration paid to the minority, see In re Cox Communications Inc. Shareholders Litigation 879 A.2d 604 (2005); In re CNX Gas Corp. Shareholders Litigation, 4 A.3d 397 (Del. Ch. 2010).

${ }^{10}$ In re DBSD North America, Inc., 421 B.R. 133, 143 n. 44 (Bankr. S.D.N.Y. 2009).

${ }^{11}$ Crown Emak Partners, LLC v. Kurz, 992 A.2d 377, 387 n. 17 (Del. 2010).
} 
hedged shareholders or creditors above a threshold of $0.5 \%$ of a company's shares or debt should be reported.

Neither of these rules or proposals, however, deals with the exercise of control rights other than formal voting rights. In particular, no rule forces an over-hedged creditor to participate in a debt exchange, even if the over-hedging were publicly known. In freeze-out tender offers, the Delaware Chancery Court has excluded votes by hedged shareholders for purposes of a majorityof-the-minority condition. ${ }^{12}$ These decisions are based on fiduciary duties of the board and parent shareholders, however, and it is not clear that they would extend to situations in which the hedged shareholder stands in opposition to the board and the parent. In particular, the Court has affirmed that even controlling shareholders are under no obligation to sell their shares, even if doing so might be beneficial to other shareholders or the corporation. ${ }^{13}$

\section{Conclusion}

This paper has shown theoretically that derivatives can create opportunities for purely valuereducing activity (over-hedging and negative voting) if derivative traders can conceal their overall positions from their counterparties. It has also argued that the institutional and legal conditions in the US are such that the threat of such activity seems real at least in out-of-bankruptcy restructurings and freezeout mergers.

This assessment of the role of derivatives is considerably less benign than that of other papers that have assumed no asymmetric information in the relationship between derivative counterparties, in particular Bolton and Oehmke (2011) and Campello and Matta (2012). Determining which assumption better describes the derivative market, or rather which parts of that market correspond to which assumption, seems an important area for future research. In as much as regulatory reforms push derivative trading into anonymous exchanges and hence closer to the assumptions of the present paper, it would be worth considering flanking measures to guard against the problems discussed here.

\footnotetext{
${ }^{12}$ See In re CNX Gas Corp. Shareholders Litigation, 4 A.3d 397, at 418 (Del. Ch. 2010); In re Pure Resources, Inc., Shareholders Litigation, 808 A.2d 421, at 426 and 446 (Del. Ch. 2002).

${ }^{13}$ Cf. In re Digex, Inc. Shareholders Litigation, 789 A.2d 1176, 1189-91 (Del. Ch. 2002) (noting that a controlling shareholder is free to block the sale of the controlled corporation to another bidder by not selling).
} 


\section{References}

1. Avellaneda, Marco, and Rama Cont. 2010. Transparency in Credit Default Swap Markets. Finance Concepts: Paris.

2. Bedendo, Mascia, Lara Cathcart, and Lina El-Jahel. 2012. In- and Out-of-Court Debt Restructuring in the Presence of Credit Default Swaps. Working paper, Bocconi University and Imperial College, available at http://ssrn.com/abstract=1666101 (visited March 15, 2012).

3. Bolton, Patrick, and Martin Oehmke. 2011. Credit Default Swaps and the Empty Creditor Problem. Review of Financial Studies 24:2617-2655 (2011)

4. Brav, Alon, and Richmond Mathews. 2011. Empty Voting and the Efficiency of Corporate Governance. Journal of Financial Economics 99:289-307.

5. Campello, Murillo, and Rafael Matta. 2012. Credit Default Swaps, Firm Financing and the Economy. Working paper, Cornell University and University of Illinois, available at http://ssrn.com/abstract=1770066 (visited March 15, 2012).

6. Chen, Kathryn, Michael Fleming, John Jackson, Ada Li, and Asani Sarkar. 2011. An Analysis of CDS Transactions: Implications for Public Reporting. Federal Reserve Bank of New York Staff Report no. 517 (September).

7. Da, Zhi and Pengjie Gao. 2009. Clientele Change, Persistent Liquidity Shock, and Bond Return Reversals After Rating Downgrades. Working paper, University of Notre Dame, available at http://nd.edu/ ${ }^{\sim}$ zda/Bond.pdf (visited March 15, 2012).

8. Hu, Henry, and Bernard Black. 2006. The New Vote Buying: Empty Voting and Hidden (Morphable) Ownership. Southern California Law Review 79:811-908.

9. ___ + 2007. Hedge Funds, Insiders, and the Decoupling of Economic and Voting Ownership: Empty Voting and Hidden (Morphable) Ownership. Journal of Corporate Finance $13: 343-367$.

10. _____ 2008. Debt, Equity and Hybrid Decoupling: Governance and Systemic Risk Implications. European Journal of Financial Management 14:663-709. 
11. Kyle, Albert. 1984. A Theory of Futures Market Manipulations. In The Industrial Organization of Futures Markets, ed. Ronald Anderson, 141-173. Lexington Mass.: LexingtonBooks.

12. . 1985. Continuous Auctions and Insider Trading. Econometrica 53:1315-1335.

13. _____, and Jean-Luc Vila. 1991. Noise Trading and Takeovers. RAND Journal of Economics 22:54-71.

14. Martin, Shaun, and Frank Partnoy. 2005. Encumbered Shares. University of Illinois Law Review 2005:775-813.

15. Peristiani, Stavros, and Vanessa Savino. 2011. Are Credit Default Swaps Associated with Higher Corporate Defaults? Federal Reserve Bank of New York Staff Report no. 494 (May).

16. Sender, Henny. 2009. Greenlight Capital founder calls for CDS ban. Financial Times, November 6, 2009.

17. Soros, George. 2010. America must face up to the dangers of derivatives. Financial Times, April 22, 2010

18. Stulz, René. 2010. Credit Default Swaps and the Credit Crisis. Journal of Economic Perspectives $24(1): 73-92$

19. Zachariadis, Konstantinos, and Ioan Olaru. 2012. The Impact of Security Trading on Corporate Restructurings. Working paper, London School of Economics, available at http://ssrn.com/abstract=165 (visited July 5, 2012). 


\section{Appendix - Proof of Lemma 1}

(1) $\theta$ is fully pinned down by rational expectations at net market demand pairs $(\hat{x}, \hat{y})$ that fully reveal the hedge fund's voting power and incentives. There are two such cases. First, as there is no noise in the securities market, low security demand $\hat{x}=x+\tilde{x} \leq \underline{x}+\tilde{x}$ fully reveals that the hedge fund does not have the voting power to implement the "wrong" decision $(x<\underline{x})$, and hence $\theta=0$. Second, as the amount of noise in the derivatives market is limited, observed net demand $\hat{y}$ puts bounds on the possible hedge fund trades and may reveal that the hedge fund strictly prefers the "wrong" or the "right" decision. In particular, if derivatives demand is sufficiently low relative to securities demand $(\hat{y}<\underline{y}+\hat{x}-\tilde{x})$, it is clear that even with low noise trader demand the hedge fund could not possibly have acquired more derivatives than securities $(y=\hat{y}-\tilde{y} \leq \hat{y}-\underline{y}<\hat{x}-\tilde{x}=x)$. In this case, the hedge fund clearly strictly prefers the "right" decision, which will hence be adopted, so $\theta=0$. A symmetric argument shows that $\theta=F(\hat{x}-\tilde{x})$ if derivatives demand is sufficiently high $(\hat{y}>\bar{y}+\hat{x}-\tilde{x})$ to reveal that the hedge fund will use all its power $(F(\hat{x}-\tilde{x}))$ to implement the "wrong" decision.

(2) At other market demand pairs $(\hat{x}, \hat{y}), \theta$ can w.l.o.g. be set to equate expected hedge fund profits for the two trades that could have generated this demand, namely $(\hat{x}-\tilde{x}, \hat{y}-\underline{y})$ (such that $x \leq y-$ a "short trade") and $(\hat{x}-\tilde{x}, \hat{y}-\bar{y})$ (such that $x \geq y-$ a "long trade"), truncated at the outer bounds of rationally possible beliefs, namely 0 and $F(\hat{x}-\tilde{x})$.

(a) For market demand pairs that are actually observed in a mixed equilibrium, this is in fact the only $\theta$ consistent with equilibrium because in order to mix, the hedge fund must be indifferent between the underlying long and short trades. For off equilibrium demand pairs, setting market makers' subjective off-equilibrium beliefs at this level achieves maximum "deterrence" of deviations from equilibrium (because at other values, either the long or short deviation would be more profitable). Finally, no pure strategy equilibrium can ever generate such market demand pairs $(\hat{x}, \hat{y})$ because the only possible pure strategey equilibrium is $(0,0)$, for which $\hat{x}$ fully reveals that $x=0 \leq \underline{x}$; at other pure strategies, the hedge fund would incur trading cost without being able to make a trading profit because its voting power and incentives are fully known and hence the hedge fund pays for the derivatives and securities exactly what it expects to get out.

(b) Truncation is immaterial because where truncation occurs, both long and short profits 
are negative with or without truncation, such that the hedge fund would not place the corresponding trades in either case. Consider first truncation at $\theta=0$. For the long trade $(x \geq y)$, expected profits $(\lambda \theta[(\hat{x}-\tilde{x})-(\hat{y}-\bar{y})]-C(\hat{x}-\tilde{x}, \hat{y}-\bar{y}))$ are negative at $\theta \leq 0$ (recall that the only cases considered here have $x>\underline{x} \geq 0$, such that $C(x, y)>0) .{ }^{14}$ Thus if equality of profits for long and short trades occurs at $\theta \leq 0$, both profits are negative at that $\theta$. But then profits for the short trade $((1-\lambda)[F(\hat{x}-\tilde{x})-\theta][(\hat{y}-\underline{y})-(\hat{x}-\tilde{x})]-C(\hat{x}-\tilde{x}, \hat{y}-\underline{y}))$ must also be negative at $\theta=0$ because short profits are decreasing in $\theta$. The argument for upper truncation at $F(\hat{x}-\tilde{x})$ is symmetric.

(c) $\theta^{*}$ equates profits for the long and short trades, i.e., $\theta^{*}$ solves $\lambda \theta[(\hat{x}-\tilde{x})-(\hat{y}-\bar{y})]-$ $C(\hat{x}-\tilde{x}, \hat{y}-\bar{y})=(1-\lambda)[F(\hat{x}-\tilde{x})-\theta][(\hat{y}-\underline{y})-(\hat{x}-\tilde{x})]-C(\hat{x}-\tilde{x}, \hat{y}-\underline{y})$.

\footnotetext{
${ }^{14}$ The economic reason is that long trading profits derive from misleading the market into thinking that the "wrong" decision may be taken $(\theta>0)$, the more the better.
} 